\title{
Who Should Regulate Disruptive Technology?
}

\author{
Marta Katarzyna KOŁACZ*, Alberto QUINTAVALLA** and Orlin YALNAZOV***
}

The primary concern of the present paper is the cost of acquiring information by judges and legislators in the process of regulating new technologies. The paper distinguishes between risky and uncertain applications of technology. A risky technology poses an obvious risk, and the problem before the regulator is one of comparing cost and benefit. We argue that the judiciary, which acquires information gratis from litigants, is better suited to the regulation of risky technologies. Uncertain technologies, on the other hand, can be harmful in ways which cannot be foreseen at the time of the technological innovation. Cost and benefit are incalculable; regulation must instead be based on subjective preferences about the degree of uncertainty that society should tolerate. Legislative law-making is designed with a view to aggregating subjective preferences. Accordingly, uncertain technologies should be regulated through statute.

\section{INTRODUCTION}

Ours is an era of technological innovation. Our law, then, must be tailored to the everchanging conditions of life. Unsurprisingly, the problem has not escaped the attention of academics. We do not propose to develop a new theory of regulation here. Instead, we discuss an institutional problem: when some new technology emerges, should it be regulated by judges or by legislators?

It is commonly thought that regulation should begin with an attempt to adapt existing laws and conditions to the specific problems posed by some innovation. ${ }^{1}$ Gregory Mandel identified three caveats to that principle. ${ }^{2}$ First, the decision maker must consider the possibility that pre-existing legal categories are inapplicable to the innovation in question. Second, legal actors should not be blindsided by the novelty of any one

\footnotetext{
* PhD researcher, Private Law, Erasmus University Rotterdam.

** $\mathrm{PhD}$ researcher, Rotterdam Institute of Law and Economics, Erasmus University Rotterdam.

*** Lecturer, University of Hull.

1 R Dworkin, Limits: The Role of the Law in Bioethical Decision Making (Indiana University Press 1996); L Moses, "Adapting the Law to Technological Change: A Comparison of Common Law and Legislation" (2003) 26 UNSWLJ 394; J Morgan, "Torts and Technology" in R Brownsword et al (eds), The Oxford Handbook of Law, Regulation and Technology (Oxford University Press 2017) 522; A Cockfield, "Tax Law and Technological Change" in Brownsword et al, ibid, 546 .

2 G Mandel, "Legal Evolution in Response to Technological Change” in Brownsword et al, supra, note 1, 225.
} 
technology. Third, it is inevitable that at least some of the legal issues that a technology poses are unforeseeable at the time of its inception. The primary concern of the present paper is with the third of Mandel's propositions. More specifically, we are concerned here with the cost of information to legislators and judges: if the judiciary can inform themselves more easily about some innovation, then they should regulate it, and vice versa. $^{3}$

Section II advances our theoretical propositions. We distinguish between risky and uncertain technologies. A risky technology poses an obvious risk, and the problem before the regulator is one of comparing cost and benefit. Critical to that exercise is the acquisition of information. We argue that the judiciary, which acquires information gratis from litigants, is better suited to the regulation of risky technologies. Uncertain technologies, on the other hand, can be harmful in ways which cannot be foreseen at the time of the technological innovation. Cost and benefit are incalculable; regulation must instead be based on subjective preferences about the degree of uncertainty that society should tolerate. Legislative law-making is designed with a view to aggregating subjective preferences. Accordingly, uncertain technologies should be regulated through statute.

Section III applies our analysis to self-driving cars. That is an example of a risky technology: the type of physical harm that self-driving cars can cause is easily identifiable in the short term. What is unknown is the probability with which accidents will occur. The judiciary perform better at acquiring this kind of information, a proposition to whose veracity the history of automotive regulation readily attests. Once a stable body of regulation emerges, considerations of taxonomy and accessibility might mean that codification becomes desirable. However, in the immediate aftermath of innovation, precedent is better.

Section IV discusses an uncertain technology, here 3D printing. We do not know what kinds of harm 3D printing might cause to our security - we are not able to predict all of its possible uses, let alone those uses' impact or their desirability. Accordingly, in deciding how to regulate 3D printers, we must decide how much uncertainty we are willing to bear. That is a question of subjective preference. At present, attempts at regulation have almost universally originated from legislatures. The courts, on the other hand, have been too slow to react: doctrinal muddles, such as the tension between regulation and the First Amendment, hamper any meaningful attempt at a judicial assessment of 3D printing. Statute is superior. Section V concludes.

\footnotetext{
3 Our framework circles on the relative institutional competence of judges and legislators. This might be a point of comparativist difficulty: the common and the civil law are animated by very different conceptions of the remit of the judicial role. We do not believe our theory to be tied to any particular legal culture. The problem that we discuss is one of informational scarcity. Information is scarce in both the civil- and the common-law world. Both legal cultures have courts and legislatures. In both, statutes have gaps that are plugged by the courts. Given these similarities, we do not believe the optimal allocation of regulatory competencies varies with legal origin. However, we cannot in good faith exclude the possibility that certain latent juridico-cultural biases have been inculcated into us in the course of our legal training. To this end, we may say that our backgrounds are mixed. Some of us trained in civilian jurisdictions then worked on Anglo-Saxon law. Others trained in common-law countries then worked in Europe. The reader might find this odd, especially given that we draw a great many examples from the jurisprudence of the American courts. Our argument does not purport to be American-centric. The selection of examples was driven entirely by considerations of availability and linguistic accessibility.
} 


\section{THEORETICAL PROPOSITIONS}

\section{Assumptions}

We do not develop a novel theory of the courts, the legislature, or technological progress. Our argument instead proceeds from assumptions. The credibility of our conclusions can accordingly never exceed that of the assumptions. For this reason, we propose to lay them bare at the outset.

\section{a. Facts}

The first assumption that we make is that it is cheaper for the courts to inform themselves about facts than it is for legislatures. The assumption, of course, is not novel - it has its origins in the Austrian literature and has gone on to become a staple in the "efficiency of the common law" literature. ${ }^{4}$ To forestall epistemological complications, ${ }^{5}$ we must define facts. By that term, we mean to denote information about elements of material reality that are immediately observable: the speed of the wind on Tuesday, the distance between Rotterdam and Amsterdam, and such like.

The stock of factual information at humanity's disposal is vast, but widely dispersed. ${ }^{6}$ Individual citizens observe a very small fraction of reality. The production of regulation begins with funnelling information from individuals to a centralised lawmaking body, be it judicial or legislative. The literature notes that the courts command an advantage. ${ }^{7}$ Why so? Every time a case comes to trial, litigants transmit information to the judge. Litigants do that because the courts offer them a valuable service in the form of dispute resolution. The same is not true of legislatures. Most citizens do not volunteer their private observations to Parliament. ${ }^{8}$ Those who do are usually interest groups, whose representations are often skewed. Therefore, we may say that the courts acquire information about facts at a lower cost than Parliament.

\section{b. Prognoses}

The second assumption that we make is that it is cheaper for the legislature to make prognoses. Why so? Prognoses, in general, entail the production of new information. For

\footnotetext{
4 See P Rubin, "Why is the Common Law Efficient" (1977) 6 JLS 51; G Priest, "The Common Law Process and the Selection of Efficient Rules" (1977) 6 JLS 61; J Goodman, "An Economic Theory of the Evolution of the Common Law" (1978) 7 JLS 393; W Landes and R Posner, "The Independent Judiciary in a Public Choice Perspective" (1975) 18 JLS 875; N Gennaioli and A Shleifer, "The Evolution of Common Law" (2007) 115 JPE 43; G Ponzetto and P Fernandez, "Case Law versus Statute Law: An Evolutionary Comparison" (2008) 37 JLS 379; R La Porta et al, "The Economic Consequences of Legal Origins" (2008) 46 JEL 285. For the Austrian perspective, see S Ratnapala, "Eighteenth Century Evolutionary Theory and Its Relevance in the Age of Legislation" (2001) 12 CPE 51, L Schwarzstein, "An Austrian Economic View of the Legal Process" (1994) 55 OSLJ 1049 and M Rizzo, "Law Amid Flux" (1980) 9 JLS 291. The assumptions originate from O Yalnazov, "Information, Precedent \& Statute" in Precedent versus Statute: Lawmaking in the Courts versus Lawmaking in Parliament (Springer 2018).

5 M Tye, "Vague Objects" (1990) 99 Mind 535 gives a flavour of the problems usually associated with describing facts.

6 F Hayek, "The Use of Knowledge in Society" (1945) 35 AER 519.

7 See the authorities cited supra, note 4, as well as C Menger, "The 'Organic' Origin of Law and the Exact Understanding Thereof' in F Nock (trans), Investigations into the Method of the Social Sciences with Special Reference to Economics (NYUP 1963); F Hayek, Law, Legislation, and Liberty: Rules and Order (Routledge 1978) 72.

8 M Faure and F Weber, "Dispersed Losses in Tort Law - An Economic Analysis" (2015) 6 JETL 163.
} 
example, we may say that a $5 \%$ increase in the price of cigarettes will produce a $10 \%$ drop in lung-cancer mortality. That information can only be produced, never observed. Accurate prognoses are costly to produce. Furthermore, the prognosticator can seldom capture more than a fraction of the social benefit of her work. ${ }^{9}$ Suppose that scientists do establish the link between cigarette prices and lung-cancer mortality. Their prognoses can then be used by the government in setting excise duties. The resultant regulation would reduce cancer mortality across society. However, the scientists who produced the initial prognosis are unable to charge those who, without the price hike, would develop cancer. As a result, we may expect fewer members of society to invest their resources, material or intellectual, into the production of prognoses. ${ }^{10}$ Absent some inducement, prognoses will be underproduced. ${ }^{11}$

In litigation, parties' willingness to pay for prognoses is tied to stakes. Stakes in individual cases are usually considerably lower than the social benefits of regulation. ${ }^{12}$ Suppose, for example, that an emphysema victim is suing a tobacco company for $£ 50,000$. The victim can win if she persuades the courts to change the law to extend liability for emphysema to cigarette manufacturers. It would clearly be useful to the victim if she could demonstrate that a $5 \%$ increase in the price of cigarettes would cause a $10 \%$ drop in the lung-cancer mortality rate. The regulation would also produce considerable benefits for society. However, if the cost of the study is $£ 100,000$, the victim will not pay for it: her private return would be negative. Since the courts have neither the legal nor the fiscal power to commission studies on their own accord, they can never acquire the necessary information. ${ }^{13}$ Parliament, conversely, can simply retain experts and pay them out of the public purse. Prognoses, then, are more accessible to parliaments than to courts.

\section{c. Preferences}

Regulation is not based purely on facts and prognoses: the regulator must also choose between competing visions of society. As Tallachini - among others - has highlighted, normative considerations shape the interpretation of scientific facts under uncertainty. ${ }^{14}$

\footnotetext{
9 K Arrow, "Economic Welfare and the Allocation of Resources for Invention" in NBER, The Rate and Direction of Inventive Activity: Economic and Social Factors (PUP 1962).

10 We do not, of course, claim that this point in novel. It is well established in the literature: see J Hirshleifer and J Riley, "The Analytics of Uncertainty and Information - An Expository Survey" (1979) 17 JEL 1375; F Machlup, The Production and Distribution of Knowledge in the United States (Princeton University Press 1962); Y Barzel, "Optimal Timing of Innovations" (1968) 50 RES 348; L Kaplow and S Shavell, "Property Rules versus Liability Rules: An Economic Analysis" (1996) 109 Harvard LR 713, 725-728. For a modern analysis of the problem, see S Morris and H Shin, "The Social Value of Public Information" (2002) 92 AmER 1521.

11 J Hirshleifer., "The Private and Social Value of Information and the Reward to Inventive Activity" (1971) 61 AmER 561.

12 S Shavell, "The Social versus the Private Incentive to Bring Suit in a Costly Legal System" (1982) 11 JLS 333.

13 For a similar argument, see G Cohen and J Greiner, "From Medical Experimentation to Non-Medical Experimentation: What Can and Cannot be Learned from Medicine as to the Ethics of Legal and Other Non-Medical Experiments" in C Fried, Medical Experimentation: Personal Integrity and Social Policy (2nd edn, Oxford University Press 2015) 213ff.

14 M Tallachini, "Medical Technologies and EU Law: The Evolution of Regulatory Approaches and Compliance" in M Cremona (ed), New Technologies and EU Law (Oxford University Press 2017).
} 
All propositions of scientific fact are uncertain to some degree. ${ }^{15}$ Uncertainty, then, is ineliminable. Propositions of scientific fact can only be put to use in lawmaking if their interpretation is framed by norms and ideologies. Accordingly, the lawmaker, if tasked with regulating discoveries, must choose between competing ideologies. ${ }^{16}$ The third assumption that we make is that the legislature can make that choice at a lower cost than the judiciary.

In modern polities, the lawmaker's personal preferences are not generally thought sufficient to ground regulatory choices. That Theresa May prefers dancing to sports would not, it is thought, be an acceptable reason to substitute Physical Education with Choreography on the state-school curriculum. Lawmakers must aggregate social preferences. In that respect, the judiciary is vastly inferior to Parliament. Judges, who are usually unelected, are reluctant to align themselves publicly with any ideology. ${ }^{17}$ Parliament, on the other hand, is designed to aggregate preferences. The legislature, then, enjoys a comparative advantage in preference aggregation.

\section{d. Applicative certainty}

The fourth assumption that we make is that judge-made law is more specific than parliament-made law. The point is well established in the literature. Thus, Kaplow points out that, under precedent, standards are converted into rules. ${ }^{18}$ As a general legal command is applied to concrete facts, the command itself becomes more specific.

\section{e. Hierarchic certainty}

The fifth - and last - assumption that we make is that Parliament's regulatory output is better structured. ${ }^{19}$ Codes, being more abstract than court judgments, tend to treat problems of delineation and taxonomy robustly. Anglo-Saxon litigators usually fight over distinctions between cases, not over problems of construction. There are comparatively fewer boundary disputes in civilian litigation. Counsels' energies are instead directed at the interpretation of words in statutes. Therefore, codified law is on the whole more structured than uncodified law.

\footnotetext{
15 J van der Sluijs, "Uncertainty, Assumptions and Value Commitments in the Knowledge-Base of Complex Environmental Problems" in A Pereira et al (eds), Interfaces between Science and Society (Green Leaf 2006).

16 H Nowotny, "The Place of People in Our Knowledge" (1999) 7 ER 247; H Nowotny et al, Re-Thinking Science: Knowledge and the Public in an Age of Uncertainty (Polity 2001).

17 TT Arvind and L Stirton, "Legal Ideology, Legal Doctrine, and the UK's Top Judges" [2016] PL 418. The judiciary's willingness to express ideological views, of course, differs from country to country - judges on the US Supreme Court are much more "ideological" than those sitting on the French Court of Cassation: J Seagal and Harold Spaeth, The Supreme Court and the Attitudinal Model Revisited (Cambridge University Press 1998). There is, however, no jurisdiction that we know of in which judges are more open about their ideologies than parliamentarians.

18 L Kaplow, "Rules versus Standards: an Economic Analysis" (1992) 42 Duke LJ 557, 611ff. See further I Ehrlich and R Posner, "An Economic Analysis of Legal Rulemaking” (1974) 3 JLS 257, 266; R Cooter, "Decentralised Law for a Complex Economy: The Structural Approach to Adjudicating the New Law Merchant" (1996) 144 UPLR 1644.

19 The argument is developed at length in, among others, O Yalnazov, "Two Types of Legal Certainty" (2018) 10 EJLS 11.
} 


\section{The regulation of disruptive technology in the short term}

Now that these assumptions are in place, it is possible to examine the relative institutional competence of the courts and the legislature in relation to disruptive technologies. When we speak of disruptive technology here, we speak of a specific capitalistic incident of scientific progress. Under ordinary market conditions, companies use scientific progress to improve their products' existing attributes: processing units become more compact, cars become quicker, screens become brighter, and so on. Technologies like these are important, but they are not disruptive. Sometimes, a company will use technology to introduce new attributes to an existing product: video becomes streamable, phones access the internet, and such like. These technologies are disruptive: they alter the market's competitive dimensions, as well as the settled behaviours of users. ${ }^{20}$ It is this latter type of innovation that concerns us here. In line with juridico-economic orthodoxy, we assume that regulation is precautionary: ${ }^{21}$ its purpose is to minimise the possibility of social harm while maximising social welfare. The simplest case concerns disruptive technologies which pose risks, in the actuarial sense of that word: there is a contingency, or a set of tractable contingencies, which may materialise with a certain probability. The informational problem before the litigator is to determine those probabilities.

\section{a. Risk}

We give a worked example of a risky technology later. It is easier to begin with an ordinary instance of technological change. Suppose that some new type of car engine is developed which permits carmakers to reduce production costs. There is a certain probability that the new engines will explode mid-journey. The regulatory problem is very simple: does the reduction in production costs match the cost of potential accidents? $?^{22}$ To devise a solution, the regulator need only come up with a law such that if the decrease in production costs is lower than the increase in accident costs, the engines will not be rolled out to market. ${ }^{23}$

One way to achieve this would be to commission experts in automotive technology to calculate risk. The courts would be ill-suited to solving the problem in this way: they would have to wait for a private party to commission the study and transmit its content to them. That would only happen if a claim arises somewhere in the polity where the amount at stake exceeds the cost of the study. Parliament is not constrained in this way. It can order the study whenever it likes.

\footnotetext{
20 In line with other authors in legal scholarship, this definition partially departs from the original narrower concept of disruptive innovation: J Bower and C Christensen, "Disruptive Technologies: Catching the Wave" (1995) 73 Harvard BR 43.

21 S Funtowicz and R Strand, "Models of Science and Policy" in T Traavik and Lim Ching (eds), Biosafety First: Holistic Approaches to Risk and Uncertainty (TWN 2009); M Tallachini, "Between Uncertainty and Responsibility: Precaution and the Complex Journey towards Reflexive Innovation" in M van Asselt et al (eds), Trade, Health, and the Environment: The European Union Put to the Test (Routledge 2014).

22 G Calabresi, The Cost of Accidents: A Legal and Economic Analysis (Yale University Press 1970).

23 W Kip Viscusi, Fatal Trade-Offs: Public and Private Responsibilities for Risk (Oxford University Press 1996).
} 
Another solution would be to permit the manufacturer to roll out the engine, and then introduce regulation if and when the need arises. In that case, the courts will - over time accumulate a lot of information about accidents. There being no regulation on the point, the law will be uncertain. This, in turn, will impel parties to litigate more. ${ }^{24}$ As they litigate, the courts will discover the causes, magnitude, and consequences of engine malfunction. The courts will receive that information at no cost. Parliament, conversely, would only be able to acquire it by paying someone to observe accidents and write reports. The cost would likely be high. Certainly, it would be positive. Therefore, the courts have an advantage.

It emerges, then, that in ex ante regulation, Parliament has an advantage, and in ex post regulation, the courts do. Whether ex ante or ex post regulation is to be preferred is a matter of context. ${ }^{25}$ It may, however, be said that under the capitalist mode of social organisation, innovation is generally favoured, ${ }^{26}$ so much so that most innovations do not require prior approval. ${ }^{27}$ In most instances, therefore, we will regulate a disruptive technology only once we discover that it is risky. Ex post regulation is the default. The courts outperform the legislature in ex post regulation. Therefore, it is best to leave the regulation of risky disruptive technologies to the courts.

\section{b. Uncertainty}

Not all regulatory problems are reducible to actuarial probability. In the simple hypothesis discussed above, the problem is one of converting "known unknowns" into "known knowns". But new technologies are also sometimes uncertain in the Knightian sense. ${ }^{28}$ They have unintended consequences. Those consequences, by definition, are unpredictable. They are "unknown unknowns".

When the Curies discovered radium in 1898, nobody could have anticipated the nuclear bomb. It would be absurd to claim that regulators in 1898 should have calculated the risk of radium being used for slaughter. Likewise, ARPANET - an early precursor of the internet - became operational in 1969. Congress did not immediately pass laws to curb the digital circulation of child pornography. In both cases, the eventualities in question - the nuclear bomb and online child pornography - were wholly unforeseeable. It is only with hindsight that we can tell how the innovations in question would come to demand regulatory attention. $^{29}$

Sometimes, the type of harm that an invention might cause is unknowable. In such instances, the theoretical sketch developed in the preceding section is of no application. Instead, the question is how much uncertainty we - as a society - are willing to tolerate.

\footnotetext{
24 G Priest and B Klein, "The Selection of Disputes for Litigation" (1984) 13 JLS 1.

25 S Shavell, "Liability for Harm versus Regulation of Safety" (1984) 13 JLS 357.

26 W Baumol, The Free-Market Innovation Machine: Analysing the Growth Miracle of Capitalism (Princeton University Press 2014).

27 The point is made very succinctly in G Terborgh, "Capitalism and Innovation" (1950) 40 AmER 118. For a modern restatement of the idea, see - among others - J Cantwell and G Santangello, "Capitalism, Profits and Innovation in the New Techno-Economic Paradigm" (2000) 10 JEE 131.

28 F Knight, Risk, Uncertainty, and Profit (Signalman 1921).

29 B Hischoff, "Hindsight $\neq$ Foresight: The Effect of Outcome Knowledge on Judgment under Uncertainty" (1975) 1 JEPHPP 288.
} 
Humans are uncertainty averse. Individuals and societies, however, differ in their degree of uncertainty aversion. ${ }^{30}$ For example, many are willing to tolerate uncertain genetic experiments. However, few would tolerate the uncertainty caused by experiments on living human beings.

There is no optimal degree of uncertainty aversion. When it comes to "blind spots", the desirability of forbearance can only be determined with hindsight. Uncertainty aversion is analogous to ideology. Statements about uncertainty, like "oughts", are unprovable. Uncertainty aversion is purely a matter of subjective preference. ${ }^{31}$

It was seen earlier that the courts are not suited to the aggregation of ideological preferences. $^{32}$ The same is true of their ability to aggregate uncertainty-related preferences. Any judge who expresses a view that a technology is too uncertain and ought to be banned - would be open to criticism on accountability grounds. For this reason, judicial responses to uncertain technologies are likely to be anaemic. There is no reason to suspect that the legislature will exhibit a systematic tendency to dodge the problems of uncertain technology. If anything, uncertain technologies are a potentially useful source of political capital for supporters and detractors alike. $^{33}$ The legislature, then, is better suited to the regulation of uncertain technologies.

\section{c. The distinction between risk and uncertainty}

The exposition thus far proceeds on the somewhat delusive assumption that it is easy, or at any rate unproblematic, to distinguish risk and uncertainty. ${ }^{34}$ Very often, advances in the socio-scientific understanding of some issue result in the conversion of uncertainty into risk. ${ }^{35}$ For example, when ARPANET was first developed, the social impact of the technology was uncertain because the social repercussions of information technology were understood poorly, if at all. ${ }^{36}$ As the internet evolved, its more nefarious uses grew apparent. We may nowadays speak of child pornography as a risk. We are familiar with the problem of digital child pornography, we monitor its incidence and we have government agencies dedicated to reducing it. In the framework of our analysis, the internet has become less uncertain and more risky. The process can also run in reverse: a risky technology can become uncertain. For example, radium was likely initially

\footnotetext{
30 Y Halevy, "Ellsberg Revisited: An Experimental Study" (2007) 75 Econometrica 503.

31 L Epstein and J Zhang, "Subjective Probabilities on Subjectively Unambiguous Events" (2000) 69 Econometrica 265.

32 R Epstein, "The Social Consequences of Common Law Rules" (1982) 95 Harvard LR 1717.

33 Since humans are uncertainty averse, large concentrations of uncertainty tend to render issues more salient. This is a type of salience bias: see S Taylor, "The Availability Bias in Social Perception and Interaction" in D Kahnemann et al (eds), Judgment under Uncertainty: Heuristics and Biases (Cambridge University Press 1982). The interpretation of salience advanced here is at its most prominent in the juridico-economic analysis of tax codes: see, among others: J Aran and D Weiss, "A Political Theory of Corporate Taxation" (1995) 105 Yale LJ 325.

34 This is true in all contexts, not just that of disruptive technology: see J Runde, "Clarifying Frank Knight's Discussion of the Meaning of Risk and Uncertainty" (1998) 5 CJE 539.

35 For an in-depth account of the process, see S Nash, "On Pragmatic Philosophy and Knightian Uncertainty" (2003) 61 RSE 251.

36 P Denning, "The Science of Computing: The ARPANET after 20 Years" (1989) 6 AS 530.
} 
conceived as risky. Once its usefulness in warfare - itself a highly uncertain process became apparent, the technology became uncertain. It is not at all straightforward to categorise technologies one way or the other; a risky technology can turn out to be uncertain and an uncertain technology may turn out to be risky.

Evidently, this poses a problem: at the time at which a new technology appears, we have no simple way of telling whether it is risky or uncertain. The problem, at the epistemological level, is this: uncertainty, as seen, entails "unknown unknowns" there are threats of whose existence we are unaware. The more "unknown unknowns" there are, the more uncertain a given technology. But we cannot ever count or measure "unknown unknowns". The best that we can do is speculate in a rough and intuitive manner.

This has two implications for our analysis. First, it raises an institutional issue. When a new technology emerges, who should decide whether it is risky or uncertain? It is thought that this authority should always rest with the legislature. Neither judges nor parliamentarians may claim to be better at identifying "unknown unknowns". However, the two differ in their aptitude for identifying the degree of uncertainty aversion that society prefers. Uncertainty aversion is quasi-ideological in nature, in that it is subjective and unable to be corroborated. It follows, then, that under our framework, the legislature should decide whether inventions are uncertain or risky. It should deal with uncertain inventions itself and delegate risky ones to the courts. Fortunately, this is readily borne out in practice - in all jurisdictions that we know of, the courts cannot normally make new rules in areas already covered by statute. Therefore, if Parliament - in line with our model - decides to regulate a technology because it is uncertain, the courts will, absent some constitutional constraint, be unable to hinder the process. Conversely, if Parliament adjudges a certain invention risky, it can delegate it to the courts through its own inaction. Since the courts cannot refuse to decide cases, they cannot - under a system based on precedent ${ }^{37}$ - refuse to produce regulation, either.

Second, and less optimistically, it is inevitable that some inventions will be miscategorised. Parliament will sometimes deem a risky technology uncertain and regulate it itself. The courts will sometimes regulate uncertain technology because the legislature has failed to act, erroneously believing the invention to be risky. Does this mean that our analysis is flawed? If the categorisation is central to the cost-effective regulation of disruptive technology - as we believe it is - then the rate of error under our paradigm would be lower than the rate of error in an institutional framework which is unguided by any paradigm, which is what we have in operation today. Accordingly, we remain convinced that our paradigm represents an improvement on the one currently in place.

\footnotetext{
37 The point is very obvious in common law contexts. We do not believe it is limited to them. In civilian countries, statutes leave gaps. The civilian courts, like their common law counterparts, have no choice but to fill them if and when they become material in litigation. In this sense, it would be correct to say that civilian systems, too, are precedential, albeit in a different way from common law countries: see N Maccormick and R Summers (eds), Interpreting Precedents: A Comparative Study (Dartmouth 1997). In general, the contemporary literature has cast doubt over the importance of legal origins: see H Spamann, "Legal Origins, Civil Procedure, and the Quality of Contract Enforcement" (2010) 166 JITE 149.
} 


\section{Disruptive technology in the long term}

The foregoing concerns the regulator's immediate response to innovations. In practice, regulation is updated periodically. ${ }^{38}$ The process often continues long after the technology has ceased to be new or disruptive. This may have implications for the relative regulatory competence of judges and parliamentarians. For instance, we said that it is better for risky technologies to be regulated by the courts. This is true in the short term, but it may be that there is a point in time at which it becomes better to switch from precedent to statute. Conversely, statute is more suited to uncertain technologies. However, there might come a point in time at which it would be better for the legislature to cede competence to the courts.

It was said earlier that courts produce more specific laws, but legislatures perform better at structuring bodies of law. Specific laws are more desirable, since they enable private parties to plan their affairs better. However, even if the law is perfectly specific, it might become difficult to predict which rule will apply to which case - a problem of hierarchic uncertainty. If such hierarchic disputes are widespread, the law becomes uncertain. Now, some areas of life require few rules. Vehicular speed is regulated in a very straightforward way. The rules are simple, like "do not drive at more than $50 \mathrm{~km} / \mathrm{h}$ in cities". They are few in number: "the speed limit is $50 \mathrm{~km} / \mathrm{h}$ in cities, $90 \mathrm{~km} / \mathrm{h}$ outside of cities, and $120 \mathrm{~km} / \mathrm{h}$ on highways". Other spheres of life are complex and require sophisticated regulation. For instance, we are not able to describe the regulation of surgical procedures, or the conduct of war, in the same way as we describe the speed limit. ${ }^{39}$

As legal complexity increases, so does the potential for overlap between the rules that constitute some corpus of law. ${ }^{40} \mathrm{We}$ assume here that statute is better structured. Therefore, once a law becomes sufficiently complex, it is best to reduce overlap through codification. Codification entails a loss of specificity, since it prevents the judiciary from tailoring regulation contextually. However, provided that the level of overlap is high, the gain in hierarchic certainty will outweigh the increase in applicative uncertainty. In the long term, precedent is desirable for simple areas of law and statute for complex ones.

How does this impact the analysis developed in the first part? First, a risky disruptive innovation is better suited to precedent. However, if regulation under precedent produces many rules, then codification becomes desirable. If, conversely, the judges devise a simple, efficacious regulatory scheme, then precedent remains optimal in the long term. Second, it was seen that an uncertain disruptive innovation is best regulated through statute. If the statute turns out to be simple, it is best to leave its specific applications to the courts in perpetuity. This would ensure that the law becomes as specific as possible. If, on the other hand, the statute turns out complex, then its development must remain the responsibility of the legislature.

\footnotetext{
38 For an economic model of the process, see R Gilbert and D Newberry, "The Dynamic Efficiency of Regulatory Constitutions" (1994) 25 RAND JoE 538. There is a fashionable argument to the effect that updating ought to be built into regulation through sunset clauses: see J Gersen, "Temporary Legislation" (2007) 74 UCLR 247 and, more generally, T Kuran and C Sunstein, "Availability Cascades and Risk Regulation” (1999) 51 Stanford LR 683.

39 See C Diver, "The Optimal Precision of Administrative Rules" (1983) 93 Yale LJ 65, Ehrlich and Posner, supra, note 18, Kaplow, supra, note 18, and C Sunstein, "Problems with Rules" (1995) 73 California LR 953.

40 Yalnazov, supra, note 19 , develops the point at length.
} 


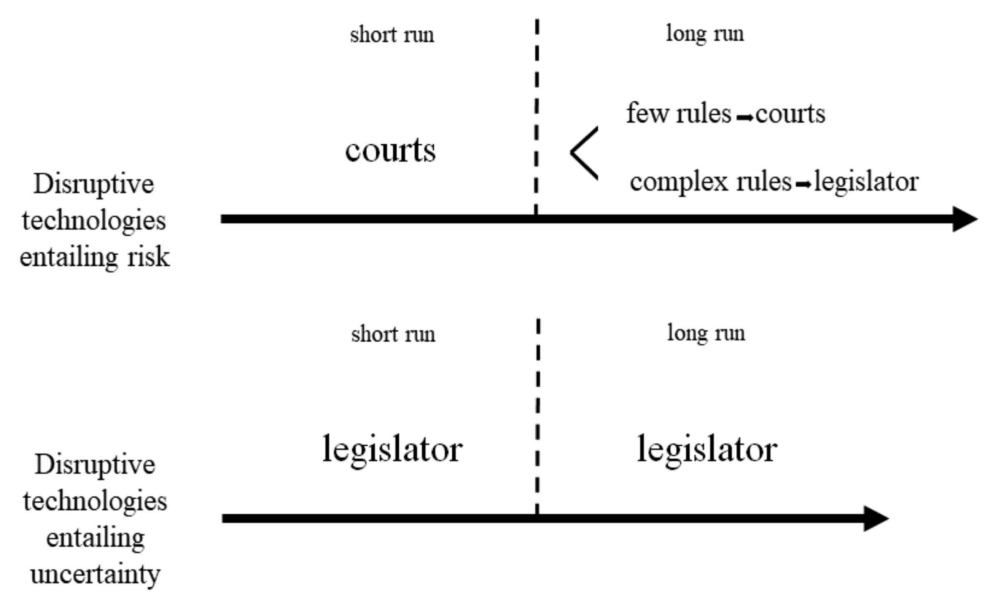

Figure 1. Theoretical arguments illustrated

\section{Summary}

We have made two theoretical arguments. First, in the short term, disruptive technologies that entail risk ought to be regulated by the courts. Disruptive technologies that entail uncertainty ought to be regulated by the legislature. The latter proposition holds true in both the long and the short term. So long as uncertainty remains unconverted to risk, the courts will be ineffective regulators. Second, in the long term, the courts should regulate risky technologies if the regulatory framework comprises a few simple rules. The legislature should control fields whose regulation comprises many complex rules. We readily concede that these are very abstract points which do not easily fit current patterns of innovation or regulation. For this reason, we now propose to examine their application in two contexts: self-driving cars and 3D printing.

\section{SELF-DRIVING CARS}

A self-driving car is a self-operating vehicle provided with the self-learning artificial intelligence (AI) system. In our framework, self-driving cars exemplify "simple" risky technologies. ${ }^{41}$ When we say risk here, we mean not the risks that inhere in any technological project - such as the likelihood of its failure to achieve its stated objectives but rather the perils that might flow from the technology being rolled out to market without any regulatory controls. Collision is the risk which - naturally - predominates any discussion of self-driving cars. Accordingly, the problem before the regulator is not one of identifying the possible sources of harm from the adoption of the new technology. The sources are by and large known; regulatory choices instead turn on assigning a probability to incidents.

\footnotetext{
41 As noted in Section II.2(c), the classification of inventions is fraught with difficulty. We cannot rule out the possibility of "unknown unknowns" existing in the comparatively simpler field of self-driving cars. Our choice of example, like any attempt at classifying inventions, is driven by intuition - though it is an intuition which we believe is widely shared.
} 
There are many classifications of self-driving cars. Some classifications focus on the levels of human interaction with automation. ${ }^{42}$ Other, on the types of drivers' control over a car. ${ }^{43}$ The industry, in turn, ${ }^{44}$ defines several levels of autonomy ranging from no autonomy to full automation. We discuss self-driving cars, considering them fully automated vehicles. The characteristics of car operation are as follows: the vehicle is entirely self-contained. It is powered by computers, interfaces, software and sensors being able to acquire and consequently use the information relevant for driving. ${ }^{45}$ The technology is expected to reduce the number of accidents on the roads. However, it is also risky: there is still a positive probability of accidents, caused by either killing a pedestrians or crashing into other vehicles.

In the context of the present submission, the question is this: who should regulate liability for the "misbehaviours" of self-driving vehicles? The prevention of collisions safety is a key concern for the development of self-driving cars. ${ }^{46}$ Under our framework, the courts should command a considerable advantage. This is so because the problem is one of "simple" risk. In substantiating that argument, we begin with an overview of the history of car-accident regulation. Thereafter, we will return to self-driving cars.

The safety issues that arise as between self-driving and non-self-driving cars are analogous to those that arose between motor cars and horses. The US case law from the early twentieth century recognised a motor car as falling under the general concept of a means of conveyance. The legal treatment of motor cars was not unlike that of horses and street cars. ${ }^{47}$ That a car could potentially frighten horses was not sufficient to render it a public nuisance. ${ }^{48}$ Additionally, the courts expressed their belief that they would be able to acquire the knowledge allowing them to regulate automobile safety. ${ }^{49}$ By and large, they succeeded. One example is the Stop, Look and Listen Rule. The standard of care for a driver was the same as that for a horseman: they had to look and listen while passing railroad crossings. Since the number of accidents kept on growing, the courts adapted the law to reflect the technological shift to cars: stopping became mandatory. ${ }^{50}$

The appearance of automobiles prompted an increase in litigation. That increase, in turn, resulted in the courts acquiring a large volume of information about automotive transport. The acquisition of information corresponded to an incremental increase in the

\footnotetext{
42 R Parasuraman et al, "A Model for Types and Levels of Human Interaction with Automation" (2000) 30 (3) IEEE Transactions On Systems, Mam, and Cybernetics - Part A: Systems and Humans 286.

43 N Merat, "Transition to Manual: Driver Behavior when Resuming Control from a Highly Automated Vehicle" (2014) 27 Transportation Research Part F 274, 275.

44 National Highway Traffic Safety Administration, "Preliminary Statement of Policy Concerning Automated Vehicles" (2013).

45 D Glancy, "Autonomous and Automated and Connected Cars - Oh My: First Generation Autonomous Cars in the Legal Ecosystem" (2015) 16 Minn JL Sci \& Tech 619, 634-640; A Lari et al, "Self-Driving Vehicles and Policy Implications: Current Status of Autonomous Vehicle Development and Minnesota Policy Implications" (2015) 16 MJLST 735, 743.

46 Lari et al, supra, note 45, 760-761; M Kyriakidis et al, "Public opinion on automated driving: Results of an international questionnaire among 5000 respondents" (2015) 32 Transportation Research Part F 127, 128.

47 Chicago v Banker, 112 Ill App 94, 97; Chicago v Collins, 175 Ill 445, 456.

48 ibid.

49 Colborne v Detroit United Ry, 177 Mich 139, 143 NW 32 (1913).

50 R Nixon, "Changing Rules of Liability in Automobile Accident Litigation" (1936) 3 L\&CP 476, 476-490.
} 
courts' regulatory output, so that, by the end, the case law established a framework for the regulation of automobiles.

Over time, the regulation of cars grew more complex. The courts do not excel at regulating complex areas of law in the long term: hierarchic overlap is inevitable. At that point, the legislator set rules on traffic communication and speed limits. ${ }^{51}$ The legislature also intervened in the torts regime. The case law revealed that the classical rules of negligence were often inadequate. ${ }^{52}$ Therefore, the statutes refined the common law in areas such as contributory negligence. ${ }^{53}$

On the whole, we may say that the appearance of cars was not met with any specific regulations: rules were adopted if and when they became necessary. Initially, the task was undertaken by the courts, which were informationally superior to the legislature they heard more cases. Over time, it became apparent that cars would require relatively complex regulation. This, in turn, led to the legislative takeover: traffic laws, statutory torts and such like superseded the general law of negligence as the main source of automotive regulation.

The regulation of self-driving cars will probably follow the same pattern. ${ }^{54}$ The discussed approaches mention remedying the harm caused by a self-driving car through the general tort of negligence or, alternatively, through statutory torts of product liability, or other duties of care involving negligence-based and strict liability. No matter which approach is eventually chosen, the approaches are all based on classical legal concepts, which the judiciary know well. Therefore, the answer to the question "who should regulate?" is this: in the short term, the judiciary should regulate automobiles, because of their informational advantages. In the long term, it may transpire that self-driving cars require complex regulation. If that turns out to be correct, then there will come a point at which the legislature should take over from the courts.

In the first instance, the courts can regulate self-driving cars through the tort of negligence. Application of the negligence-based liability to accidents caused by selfdriving cars would hinge on the definition of "due care". The threshold for a self-driving car driving on the streets will probably be extremely high. ${ }^{55}$ Applying negligence to machines is problematic because the standard was developed for humans and also because machines cannot compensate their victims. ${ }^{56}$ Since there is no human driver, the courts would have to ask whether the self-driving car performed as it should have. ${ }^{57}$ Unless the liability can be directly attributed to a person steering the car, for example through the navigation system, the question will always be whether the car was manufactured and designed with due care or, failing that, whether the owner or manufacturer - qua principal - exerted due care.

\footnotetext{
51 C Berry, The Law of Automobiles (4th edn, C\&C 1924) 36.

2 Cf L Friedman, A History of American Law (S\&S 2005) 360-362.

53 Nixon, supra, note 50, 483.

54 K Graham, "Of Frightened Horses and Autonomous Vehicles: Tort Law and Assimilation to Innovations" (2012) 52 SCLR 101, 130.

55 Arnold v Reuther, 92 So 2d 593, 596 (La Ct App 1957).

56 K Colonna, "Autonomous Cars and Tort Liability" (2012) 4 JLTI 81, 103.

57 Lari et al, supra, note $45,750-752$.
} 
Liability could be imposed under the product liability regime. That is so because selfdriving cars exhibit similarities to other products. They may have flaws and defects. Alternatively, it may be said that cars can learn to make decisions. Therefore, the manufacturer of the car, or its owner, might be assumed to control the car. Accordingly, the manufacturer (if it supplies the car with AI) would need to prove that it exerted due care in detecting and disclosing flaws. ${ }^{58}$

Alternatively, there is an obvious analogy with vicarious liability. Should manufacturers observe dangerous behaviour, they must take precautionary action. Thus, there would be negligence-based liability for damage caused by the self-driving car where it can be shown that the car had a propensity to cause a particular type of harm or injury and that the manufacturer or user were aware of that dangerous propensity. The liability of the manufacturer or the owner would be strict if the self-driving car were found to be an agent for its principal. ${ }^{59}$

In this context few observations regarding the application of the existing rules have been made. We do no exhaust them here. As far as negligence-based liability in the manufacture of software is concerned, defects might be difficult to prove. The plaintiff would need to prove the error in the software algorithm. ${ }^{60}$ Second, it could be difficult to show that a defect was present when the car left the production facility. ${ }^{61}$ Under a system of strict liability, it might be difficult to pinpoint the specific defect which caused an accident. Suppose a self-driving car decides, on its own, that it is better to hit a pedestrian than to cause a chain crash. The circumstances would not logically suggest that there was a defect. $^{62}$ In the end, the car chooses the lesser evil. Additionally, lack of accident evidence might render foreseeability unprovable. Furthermore, it might be difficult to show that there was an alternative design. ${ }^{63}$ In consequence, the injured party could be left without a remedy. As far as the liability aspects in the principal-agent relationship are concerned, it can be questioned whether a car can have a proclivity to cause a particular type of harm or that the user was aware of that proclivity. It might be expected that manufacturers and users will seldom anticipate danger. For the same reason, it could also be difficult to say when a machine is under somebody's control or within the course of some form of employment. In consequence, the owner of the car or the manufacturer would not be able to escape liability. This will force the regulator to choose between different approaches to balance risks. ${ }^{64}$

In light of the foregoing, legislators have enacted or proposed solutions. Most focus on manufacturers, who are the cheapest cost-avoiders. Due to that there are suggestions for the full strict liability of a manufacturer. ${ }^{65}$ Alternatively, there is a proposal to hold the

58 See J Gurney, "Sue My Car Not Me: Product Liability and Accidents Involving Autonomous Vehicles" (2013) 2 JLTP 247

59 U Pagallo, The Laws of Robots (Springer 2013) 121-134.

60 Gurney, supra, note 58, 259-260.

61 P Cerka et al, "Liability for Damages Caused by Artificial Intelligence” (2015)31 CL\&SR 376, 386.

62 J Brodsky, "Autonomous Vehicle Regulation: How an Uncertain Legal Landscape May Hit the Brakes on SelfDriving Cars" (2016) 31 BTLJ 851, 863-864.

63 D Owen, "Proof of Product Defect" (2004) 93 Kentucky LJ 1.

64 M Lohmann, "Liability Issues Concerning Self-Driving Vehicles" (2016) 7 EJRR 335.

65 A Brown, "Blame It on the Machines: How Autonomous Vehicles Will Impact Allocation of Liability Insurance and the Resulting Impact on the Legal Community" (2016-2017) 95 NCLRev Addendum 29, 40-46. 
manufacturer liable proportionally to the learning ability of the AI system. In other words, the longer a manufacturer supplies the car with the information to make it selfdriving, the greater the manufacturer's responsibility. ${ }^{66}$ Another alternative suggests that strict liability should be limited to the value of their robot's portfolio, which is like a special fund or stock. ${ }^{67}$ Moreover, for example, the State of Michigan introduced the law limiting the liability of the manufacturer if a third party alters software. ${ }^{68}$ Other proposals mention obligatory insurance ${ }^{69}$ including insurance against damage not liability ${ }^{70}$ or adapting the concept of negligence to changing circumstances. ${ }^{71}$ There are also propositions to employ limited liability companies for the operation of autonomous systems. $^{72}$ These solutions concern legislative initiatives that aim to correct the shortcomings of the current system. ${ }^{73}$ If that approach is preferred, then regulation will be predominantly statutory.

To sum up, a few observations can be made. First, the risks of automotive innovations are generally appraised after a product has been brought to market. In order to regulate risky technologies, the starting point should be the existing body of law and judges' ability to acquire information about the operation of the new technology and the necessary regulatory adaptations. Second, the legislator should step in to correct the system once lacunae appear. Therefore, the general regulation of automotive risks should - for now - be entrusted to the judiciary. Past experience and current legislative proposals indicate that, once the field matures, it will become sufficiently complex to warrant a switch to statute. Accordingly, the legislature is presently limiting itself to limited legal commands, leaving information about the specific workings of the AI system to be acquired incrementally by the judiciary.

\section{3D PRINTING}

$3 \mathrm{D}$ printing is an innovation with disruptive potential. A 3D printer can produce anything, from ceramics to human cells. All that is necessary is a computer and a CAD file. The implications of 3D printing are not fully understood. ${ }^{74}$ Sometimes, the consequences are obvious (ceramics). Sometimes, they are unpredictable (guns). Since

\footnotetext{
66 European Parliament Committee on Legal Affairs, Report with Recommendations to the Commission on Civil Law Rules on Robotics (2017).

67 Pagallo, supra, note 59, 133-134.

68 Bill Number SB 663 (2013).

69 Colonna, supra, note 56, 118; Pagallo, supra, note 59, 118; D Vladeck, "Machines without Principals" (2014) 89 Washington LR 117, 129, 146-150.

70 Lohmann, supra, note 64, 339.

71 See R Abbott, “The Reasonable Computer: Disrupting the Paradigm of Tort Liability" (2018) 86 GWLR 1; and S Wenzel "Not Even Remotely Liable: Smart Car Hacking Liability" (2017) 2017 UIJLTP 49.

72 See S Bayern, "The implications of Modern Business-Entity Law for the Regulation of Autonomous Vehicles" (2016) 7 EJRR 297, 302-304.

73 See generally: J Beatson, "Has The Common Law a Future" (1997) 56 CLJ 291, 301

74 A Lewis, "The Legality of 3D Printing: How Technology is Moving Faster than the Law" (2014) 17 TJTIP 303. See further J Danielczyk, “3D Printed Guns: A Developing Technology with Dangerous Potential” (2017) 17 PJTLP 17; D Westermeyer, "The State Department Can Gun Down 3D Printed Firearms" (2017) 13 WJLTA 201. For an intellectual property angle, see B Depoorter, "Intellectual Property Infringements \& 3D Printing: Decentralised Piracy" (2014) 65 Hastings LJ 1483. For a product liability analysis, see N Engstrom, "3D Printing and Product Liability: Identifying the Obstacles" (2013) 162 UPLR 35.
} 
3D printing is an invention with many unforeseeable applications, we classify the technology as "uncertain". 75

Because 3D printing is a facilitative technology, we cannot easily anticipate the totality of its applications. To maintain tractability, we focus on security risks. For instance, is it possible for an ordinary person to manufacture a gun, such as a revolver, an assault rifle, or even a grenade, in the privacy of their own home? If so, 3D printing would thwart gun regulation. ${ }^{76}$ We cannot assign a numerical probability to that risk. Nor can we claim that this exhausts the kinds of harm that 3D printing may generate. The Peace Research Institute, for instance, notes that 3D printing will also permit Western military technology to be copied cheaply by enemy militants. Similarly, it is not possible to rule out the use of $3 \mathrm{D}$ printing to create larger weapons, such as drones or even rocket launchers. ${ }^{77} 3 \mathrm{D}$ printing, then, is uncertain. The uncertainty is not unipolar: 3D printing may also, plausibly, usher in a new Industrial Revolution. ${ }^{78}$

There is thus a commonality between this example and the one developed in the preceding section: the task before the regulator is to measure the expected value of $3 \mathrm{D}$ printing to the economy against the expected costs of the increased incidence of security incidents. There is, however, a difference, since the long-term social benefits of 3D printing and the likelihood of security incidents are incalculable. The question, then, is one of uncertainty aversion: how much innovation are we willing to tolerate if there is an unknown probability of it being used to perpetuate atrocities? As we argued earlier, the courts are ill-suited to this kind of decision. ${ }^{79}$ Gun control is ideologically charged. The judiciary are reluctant to voice ideological opinions. Legislatures, conversely, aggregate ideological preferences. Accordingly, it is best for uncertain technologies - of which 3D printing is one - to be regulated by statute.

$3 \mathrm{D}$ printing opens new avenues of weapon production. There is a legitimate social interest in controlling weapon production. For instance, the manufacture of a working $3 \mathrm{D}$ gun that is undetectable by standard metal detectors has repeatedly caused alarm. ${ }^{80}$ The existing gun licencing framework is based on the imposition of controls on one component, the weapon's frame. Frames can be 3D printed: forgery becomes costless. It might be necessary to introduce a licensing scheme which focuses on some other, non3D-printable component. ${ }^{81}$ It is far from easy to see how this can be done without widescale disruptions to the existing enforcement framework.

\footnotetext{
75 See B Berman, "3D Printing: The New Industrial Revolution” (2012) 55 BH 155. We are eager to stress that our classification is not immune to objections: see supra, note 23, as well as Section II.2(c). It is virtually inevitable that if 3D printing is used for a long time, "unknown unknowns" will become "known unknowns". Uncertainty will be converted to risk. At that point, the technology will no longer be certain. Insofar as that point in time is at some remove from the present, we are fairly confident that 3D printing is an apposite example of an uncertain technology.

76 K McMullen, "Worlds Collide When 3D Printers Reach the Public: Modelling a Digital Gun Control Law after the Digital Millenium Copyright Act” (2014) Michigan State Law Review 187.

77 M Fey, $3 D$ Printing and International Security (PRIF Report No 144, 2017).

78 B Garrett, “3D Printing: New Economic Paradigms and Strategic Shifts” (2014) 5 GP 70.

79 A similar argument is made in another contribution to this special issue: see K Heine and S Li, "What Shall We Do with the Drunken Sailor? Product Safety in the Aftermath of 3D Printing" (2019) EJRR (forthcoming).

80 J Jacobs and A Haberman, "3D-printed firearms, do-it-yourself guns, \& the Second Amendment" (2017) 80 L\&CP 129.

81 P Jensen-Haxel, "3D Printers, Obsolete Firearm Supply Controls, and the Right to Build Self-Defense Weapons under Heller" (2012) 42 GGULR 447.
} 
Representative Steve Israel proposed to amend the renewed 1988 Undetectable Firearms Act to criminalise firearms whose production is undetectable. ${ }^{82}$ The need for regulation manifested powerfully when Cody Wilson published software that enabled users to print a 3D plastic gun. Everyone could easily manufacture firearms at a relatively low cost. ${ }^{83}$

3D printing technology has sparked a review of gun-control laws. The current regulatory framework was devised at a time when few individuals could produce weapons. ${ }^{84}$ This led the legislature to focus on possession and distribution. Only a few laws regulate 3D firearms. Certain agencies have tried to advance preemptive regulation. ${ }^{85}$ For instance, the City Council of Philadelphia adopted an ordinance banning the use of 3D printing for manufacturing arms: "[n]o person shall use a threedimensional printer to create any firearm, or any piece or part thereof, unless such person possesses a license to manufacture firearms under Federal Law, 18 U.S.C. $§ 923$ (a)" ${ }^{86}$ Similarly, the US State Department took immediate action when Wilson posted the Liberator's blueprint on the internet. ${ }^{87}$

In line with our prediction, the immediate regulatory response to the new technology has come from the legislature. Gun control is a rich skein of political capital. The judiciary, on the other hand, struggle to aggregate ideological and uncertainty-related preferences about guns. Any attempt at judicial regulation would require a balance to be struck between free speech, public safety, and the right to bear arms. The judicial branch is - understandably - reluctant to intervene. ${ }^{88}$

We said earlier that complex regulation usually becomes hierarchically uncertain if left in the hands of the judiciary. ${ }^{89}$ Firearms regulation is no exception: the principal doctrinal challenge to regulating 3D weapons emanates from case law. Legislation regulating 3D printed guns may infringe on the First and Second Amendments to the US Constitution. The First Amendment relates to the freedom of speech, which is interpreted broadly. ${ }^{90}$ The First Amendment covers digital blueprints and CAD files. Yet, the level of protection that CAD files enjoy depends on how the courts characterise them. ${ }^{91}$ For example, if the courts classify CAD files as pure speech, then they will be afforded the highest level of protection. ${ }^{92}$ Clarity, however, is difficult to attain: the law will remain

\footnotetext{
82 Lewis, supra, note 74.

83 Jacobs and Haberman, supra, note 80.

84 J Berkowitz, "Computer-Aided Destruction: Regulating 3D-Printed Firearms Without Infringing on Individual Liberties" (2018) 33 BTLJ 53.

85 3D Firearms Prohibition Act (US Congress Bill HR 7115, 2017-8).

86 Defense Distributed sued the State Department, arguing that the request to remove the blueprint involves the breach of the first two amendments to the US Constitution: Phila, Pa, Code $\S 10-2002$ (2018).

87 Defense Distributed v Department of State, 838 F 3d 451, 462 (2016).

88 McMullen, supra, note 76.

89 The point is latent in the US District Court's reasoning in Reno. There, the court acknowledged that the lack of government regulation had wrought chaos on the internet. It then emphasised the difficulty of a court striking an appropriate balance between freedom of expression and risks such as the protection of minors: American Civil Liberties Union v Reno (1996) 929 F Supp 824, 883.

90 J Blackman, “The 1st Amendment, 2nd Amendment, and 3D Printed Guns” (2013) 81 TLR 479.

91 J Cosans, "Between Firearm Regulation and Information Censorship: Analyzing First Amendment Concerns Facing the World's First 3D Printed Plastic Gun" (2013) 22 AUJGSCPL 915.

92 Berkowitz, supra, note 84 .
} 
unsettled until such time as the legislature decides to act and a challenge is put before the Supreme Court.

The Second Amendment can potentially cover printed guns. In District of Columbia $v$ Heller, ${ }^{93}$ the Court interpreted the right to possess arms narrowly: it only covered weapons which are "typically possessed by law-abiding citizens". 94 It follows that only those firearms that are popular in the market, and not the "dangerous and unusual"95 ones, are protected under the Second Amendment. The US District Court of Maryland has concretely applied this line of reasoning, the so-called "in common use" test, to assault-style long guns. ${ }^{96}$

It seems that regulations governing 3D printed weapons may pass the "in common use" test only if a significant section of the population is familiar with this type of arms. Because of this, a regulation restricting, or even banning, the production of 3D printed guns can only be adopted in the infancy of the technology. Yet, one may also construe "dangerous and unusual" to refer to design rather than mode of production. Should this turn out to be the case, all regulation is foreclosed.

It is evident that the courts - whatever their informational advantages - are not wellsuited to the regulation of an uncertain technology. To the judiciary, a personal right to manufacture weaponry is "constitutional terra nova". 97 As any student of common law legal history will attest, the rapid production of concrete regulatory solutions to ideologically contested social problems is not the judiciary's forte. In fact, under the American constitutional framework, the regulatory process has been impeded by the judiciary. Being unable to aggregate preferences about uncertainty, the courts will doubtless be forced to decide cases on the basis of first principles - the right to bear arms, freedom of speech, and such like. Those principles, though no doubt important to Americans, will also operate to obscure the central regulatory issue, which is the desirability of 3D gun printing.

\section{Conclusion}

The time is opportune to conclude. We began by drawing a distinction between technologies that are risky and technologies that are uncertain. Risky technologies are best regulated by the judiciary. This is so because litigation is the most cost-effective method of funnelling information from litigants to the lawmaker. Uncertain technologies are different, in that regulatory choices have to be made on the basis of subjective preference rather than objective facts. The legislature, which is designed with a view to aggregating social preferences, is superior to the courts. We also drew a distinction between the short and the long term. In the short term, the main regulatory problem is the acquisition of information. In the long term, attention shifts to problems of hierarchy,

\footnotetext{
District of Columbia v Heller, 554 US 570 (2008).

ibid, 625 .

ibid, 627.

96 Kolbe v O'Malley, 42 F Supp 3d 768, 788-89 (D Md 2014).

97 Jensen-Haxel, supra, note 81, 473.
} 
overlap, and taxonomy. Accordingly, the more complex an area of law becomes, the likelier it is that codification - with its superior structure - will become desirable.

We then moved to apply the theory to self-driving cars. Self-driving cars are risky: there is a positive probability that they will injure or kill humans. The history of automotive regulation shows that, in the short term, the courts are well-suited to solving regulatory challenges. As the law matures, judge-made rules begin to overlap, prompting a shift to statute. It is likely that self-driving cars will follow the same pattern: at first, the courts will command an advantage due to their informational superiority. Once a stable body of legal principles emerges, codification will be preferable.

We also examined the applications of the theory to an uncertain technology, 3D printing. The set of potential risks that 3D printers pose is open-ended. It is not possible to ascertain the actuarial probability that harm will occur. Accordingly, the problem is one of aggregating social preferences about uncertainty. Regulation in the field is nascent. In line with our predictions, the more promising regulatory initiatives originate from legislative bodies. The courts, stuck between entrenched constitutional doctrines and the need to regulate harm, have been slow to respond. Evidently, the legislature commands an advantage.

These examples, of course, are neither conclusive nor exhaustive. Much remains to be done. We hope, however, that our theoretical framework - schematic as it is for now represents a small advance in our understanding of the institutional dynamics of technological regulation. 